Journal of

Molecular Microbiology

and Biotechnology
J Mol Microbiol Biotechnol 2018;28:37-46

DOI: $10.1159 / 000487137$
Received: October 9, 2017

Accepted: January 22, 2018

Published online: April 4, 2018

\title{
Isolation and Characterization of a Lytic Bacteriophage (vB_PmiS-TH) and Its Application in Combination with Ampicillin against Planktonic and Biofilm Forms of Proteus mirabilis Isolated from Urinary Tract Infection
}

\author{
Mahsa Yazdi $^{a}$ Majid Bouzari ${ }^{a}$ Ezzat Allah Ghaemi ${ }^{b}$ \\ ${ }^{a}$ Department of Biology, Faculty of Sciences, University of Isfahan, Isfahan, Iran; 'b Department of Microbiology, \\ Golestan University of Medical Sciences, Gorgan, Iran
}

\section{Keywords}

Bacteriophage · Planktonic - Biofilm - Proteus mirabilis .

Urinary tract infection $\cdot$ Ampicillin

\begin{abstract}
Proteus mirabilis is one of the most common causes of urinary tract infection (UTI), particularly in patients undergoing long-term catheterization. Phage vB_PmiS-TH was isolated from wastewater with high lytic activity against $P$. mirabilis (TH) isolated from UTI. The phage had rapid adsorption, a large burst size ( 260 PFU per infected cell), and high stability at a wide range of temperatures and $\mathrm{pH}$ values. As analyzed by transmission electron microscopy, phage vB_PmiSTH had an icosahedral head of $\sim 87 \times 62 \mathrm{~nm}$ with a noncontractile tail about $137 \mathrm{~nm}$ in length and $11 \mathrm{~nm}$ in width. It belongs to the family Siphoviridae. Combination of the phage vB_PmiS-TH with ampicillin had a higher removal activity against planktonic cells of $P$. mirabilis $(\mathrm{TH})$ than the phage or the antibiotic alone. Combination of the phage at a multiplicity of infection of 100 with a high dose of ampicillin $(246 \mu \mathrm{g} / \mathrm{mL})$ showed the highest biofilm removal activity after $24 \mathrm{~h}$. This study demonstrates that using a combination of phage and antibiotic could be significantly more effective against planktonic and biofilm forms of $P$. mirabilis (TH).
\end{abstract}

(c) 2018 S. Karger AG, Basel

\section{KARGER}

(c) 2018 S. Karger AG, Basel

E-Mail karger@karger.com

www.karger.com $/ \mathrm{mmb}$

\section{Introduction}

Proteus mirabilis is one of the most common causes of urinary tract infection (UTI) in individuals with longterm indwelling catheters, complicated UTI, and bacteremia among the elderly [Burall et al., 2004; Jacobsen and Shirtliff, 2011]. P. mirabilis accounts for $12 \%$ of complicated UTIs, being the third most common cause of UTI and the second most common cause of catheter-associated bacteriuria in long-term catheterized patients. P. mirabilis strains are able to form biofilm, a structure resistant to commonly used antibiotics [Maszewska et al., 2016]. Due to the production of biofilm on surfaces, treatment of $P$. mirabilis infections with common medications becomes difficult. Therefore, there is a need for developing new strategies for biofilm prevention and removal.

Bacteriophages are viruses that infect bacteria; they utilize their machinery to replicate intracellularly and are finally released from the host by cell lysis [Carson et al., 2010]. Previous studies suggest that bacteriophages could be applied as antibiofilm agents [Cerca et al., 2007; Sil-

\footnotetext{
Majid Bouzari

Department of Biology, Faculty of Sciences, University of Isfahan Hezar Jereeb Street

Isfahan 81746-73441 (Iran)

E-Mail bouzari@sci.ui.ac.ir
}

Ezzat Allah Ghaemi

Department of Microbiology, Golestan University of Medical Sciences Gorgan 4934174515 (Iran)

E-Mail eghaemi@yahoo.com 
lankorva et al., 2004]. Phages produce depolymerase enzymes that degrade a biofilm's exopolysaccharide matrix and cause complete disruption of the biofilm [Harper et al., 2014]. Treatment of biofilms with phages might be difficult due to emergence of phage-resistant strains and the poor penetration of phages within older biofilms caused by the presence of a large number of metabolically inactive cells. Thus, biofilm treatment with a combination of chemically distinct antimicrobials might be an effective strategy for eliminating these problems [Chhibber et al., 2013]. Similar to multidrug therapy, combined phage-drug therapy is less likely to fail due to resistance, as bacteria resistant to one agent can still be killed by the second [Carson et al., 2010; Kirby, 2012; Nzakizwanayo et al., 2016].

The objective of this study was to isolate and characterize a new lytic phage from wastewater that infects $P$. $m i$ rabilis. The study also investigated the lytic activity of the phage and its combination with antibiotics against the bacterial planktonic cells as well as biofilms under controlled conditions in vitro.

\section{Results}

\section{Confirmation of P. mirabilis by $16 S$ rRNA Gene}

\section{Sequencing}

The strain properties first were identified by biochemical tests as referred to in Experimental Procedures. Furthermore, $16 \mathrm{~S}$ rRNA gene sequencing was performed and deposited in GenBank (accession No.: KX446920). The biochemical and sequencing analysis results supported evidence for the isolate $\mathrm{TH}$ as a $P$. mirabilis strain.

\section{Phage Isolation}

The lytic phage was isolated from sewage and recognized by the double-layered technique. The phage has formed clear plaques on P. mirabilis (TH) lawn. It was further designated as vB_PmiS-TH, according to Kropinski et al. [2009].

\section{Phage Host Range}

Among 21 different bacterial species, only P. mirabilis (TH) and P. mirabilis ATCC 43071 were susceptible to vB_PmiS-TH (Table 1). The results show that vB_PmiS$\mathrm{TH}$ has a narrow host range.

\section{Thermal and $p H$ Stability}

The phage vB_PmiS-TH has its maximum infection activity at $37^{\circ} \mathrm{C}$ for $1 \mathrm{~h}$ at $\mathrm{pH}$. The differences in titers
Table 1. Lytic activity of the bacteriophage vB_PmiS-TH on different bacterial species

\begin{tabular}{rll}
\hline Sample No. & Bacterial strain & Activity \\
\hline 1 & Proteus mirabilis TH & + \\
2 & Proteus mirabilis p30 & - \\
3 & Proteus mirabilis p299 & - \\
4 & Proteus mirabilis p62 & - \\
5 & Proteus mirabilis p394 & - \\
6 & Proteus mirabilis ATCC43071 & + \\
7 & Acinetobacter baumannii 19606 & - \\
8 & Klebsiella pneumoniae 700603 & - \\
9 & Klebsiella pneumoniae 1402 & - \\
10 & Pseudomonas aeruginosa 27853 & - \\
11 & Pseudomonas aeruginosa PA01 & - \\
12 & Escherichia coli ATCC2522 & - \\
13 & Escherichia coli B355 & - \\
14 & Escherichia coli B323 & - \\
15 & Escherichia coli B352 & - \\
16 & Escherichia coli B28 & - \\
17 & Escherichia coli B461 & - \\
18 & Escherichia coli B193 & - \\
19 & Enterococcus faecalis 29211 & - \\
20 & Staphylococcus aureus 2895 & - \\
21 & Staphylococcus epidermidis 1435 & - \\
\hline & & \\
\hline
\end{tabular}

of the phages at temperatures ranging from 37 to $50^{\circ} \mathrm{C}$ were not significant. At other temperatures, the differences were significant $(p<0.05)$. The phage was completely inactivated when heated to $80^{\circ} \mathrm{C}$ (Fig. 1a). It retained its maximum activity at $\mathrm{pH} 7$ for 1 and $24 \mathrm{~h}$, and the difference in the titers was not significant. At $\mathrm{pH}$ values ranging from 3 to 11 , the viability of vB_PmiS-TH was significantly decreased after $24 \mathrm{~h}$ compared to $1 \mathrm{~h}$ ( $p \leq 0.05$ to $p \leq 0.001)$. The phage was inactivated at low (2) and high (12) $\mathrm{pH}$ values (Fig. 1b).

\section{Analysis of the Adsorption Rate and Burst Size of the} Phage $v B \_P m i S-T H$

The effects of $\mathrm{Mg}^{2+}$ and $\mathrm{Ca}^{2+}$ ions on the adsorption rate of the phage are shown in Figure 2a. The statistical analyses showed significant differences in adsorption between phages treated with $\mathrm{Mg}^{2+}$ or $\mathrm{Ca}^{2+}$ ions and controls at different times.

The single-step growth assay results showed a latent period of $\sim 20 \mathrm{~min}$ and a burst size of $\sim 260$ PFU/infected cell for vB_PmiS-TH (Fig. 2b). The results demonstrate that vB_PmiS-TH is a lytic phage with a large burst size.
Yazdi/Bouzari/Ghaemi 


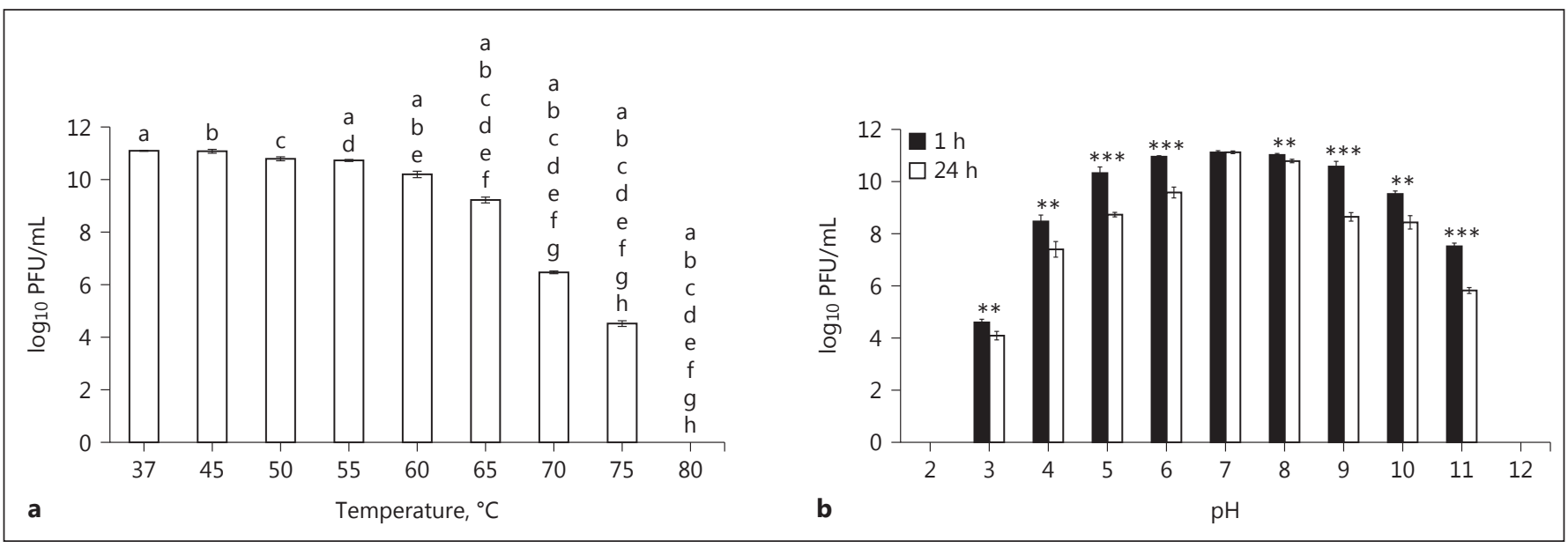

Fig. 1. Stability assay of the phage vB_PmiS-TH. a Stability at various temperatures for $1 \mathrm{~h}$. Data were analyzed by one-way repeated-measures ANOVA. Differences in titers of the virus between columns with the same letters were significant $(p<0.05)$. b Phage vB_PmiS-TH titer changes under different $\mathrm{pH}$ values for 1 and $24 \mathrm{~h}$. Asterisks indicate significant differences in phage titers between 1 and $24 \mathrm{~h}$ for different $\mathrm{pH}$ values. Student's $t$ test was used: ${ }^{* *} p \leq 0.01,{ }^{* * *} p \leq 0.001$.

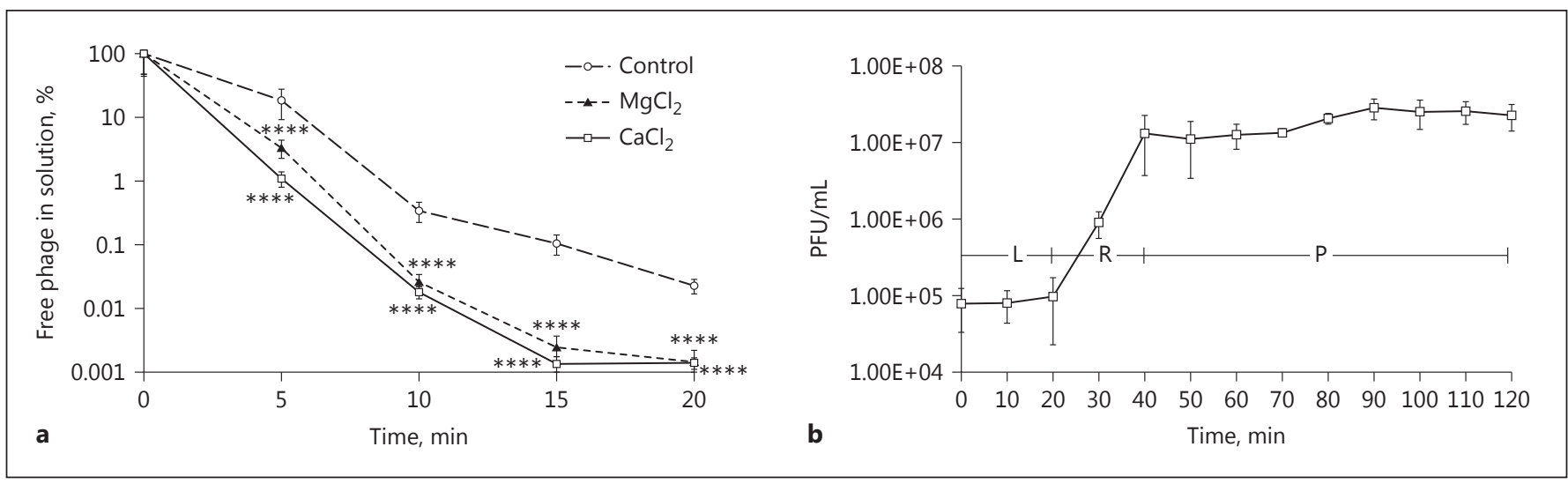

Fig. 2. Determination of the adsorption rate and burst size of the phage vB_PmiS-TH. a The effect of divalent metal ions on the adsorption rate was determined by $10 \mathrm{mM} \mathrm{CaCl}_{2}$ or $\mathrm{MgCl}_{2}$ added to the mixture of phage vB PmiS-TH and P. mirabilis (TH). Asterisks indicate significance differences in phage adsorption under cationic ions in comparison with that of controls as measured by two-way ANOVA (**** $p \leq 0.0001)$. b One-step growth experiment. The latent time and burst size of the phage $\mathrm{vB} \_\mathrm{PmiS}-\mathrm{TH}$ were inferred from the curve with a triphasic pattern. $\mathrm{L}$, latent phase; $\mathrm{R}$, rise phase; $\mathrm{P}$, plateau phase.

\section{Electron Microscopy of the Phage}

An electron micrograph of vB_PmiS-TH is shown in Figure 3. It had an icosahedral head of $\sim 87 \times 62 \mathrm{~nm}$ with a noncontractile tail about $137 \mathrm{~nm}$ in length and $11 \mathrm{~nm}$ in width. Based on its morphological characteristics, the phage was identified as a member of Siphoviridae.

\section{Restriction Fragment Analysis of the Genomic DNA}

The restriction pattern of the genomic DNA is shown in Figure 4. The phage was digested by the EcoRI, HindIII, NdeI, and EcoRV restriction enzymes. However, the phage genome appeared to be resistant to digestion by the PstI restriction enzyme. Based on the digestion profiles of the restriction enzymes, the genome of phage $\mathrm{vB}$ _PmiS$\mathrm{TH}$ was a double-stranded DNA with a size of $\sim 45 \mathrm{kbp}$. 

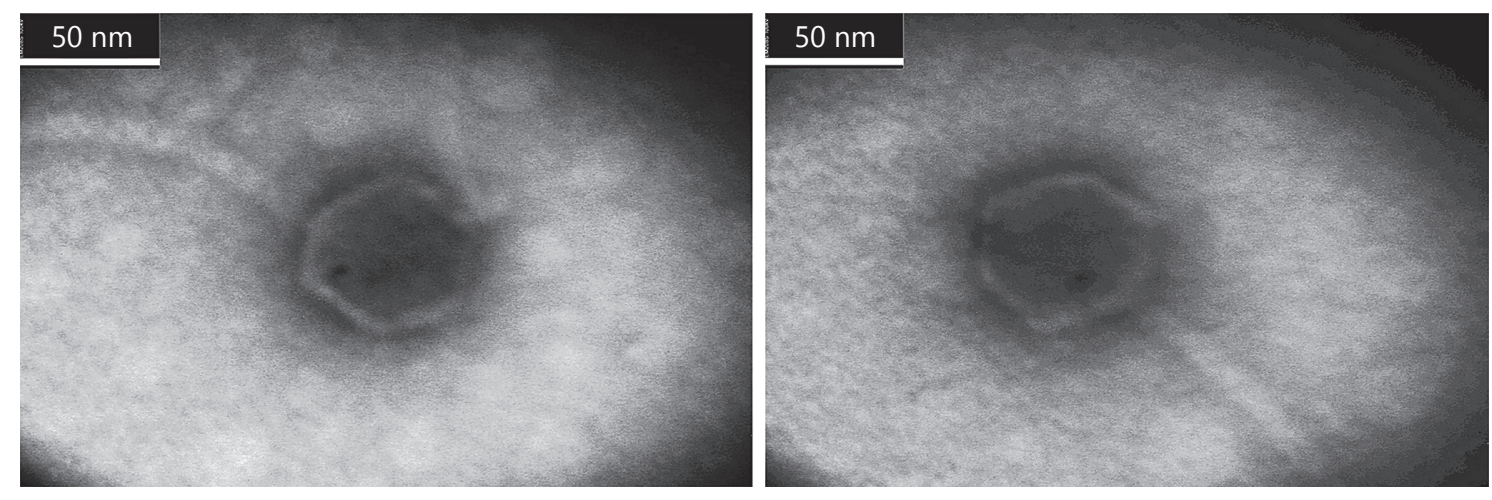

Fig. 3. Electron micrographs of the phage vB_PmiS-TH.

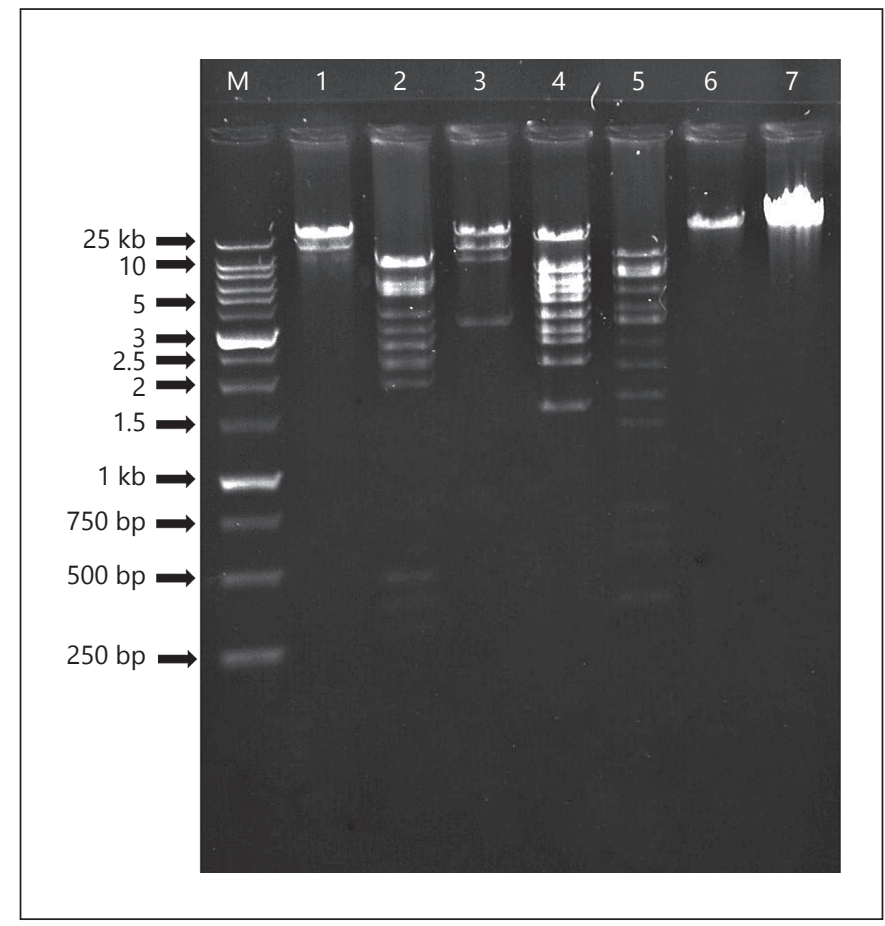

Fig. 4. Restriction fragment analysis of the phage's genomic DNA. It was digested with EcoRI (lane 1), EcoRV (lane 2), HindIII (lane 3), BamHI (lane 4), NdeI (lane 5), and PstI (lane 6). Control: genomic DNA (lane 7). M, marker (Cinacolon, Iran).

Susceptibility of Planktonic cells of P. mirabilis (TH) to $v B \_P m i S-T H$

Planktonic cultures of $P$. mirabilis $(\mathrm{TH})$ proved to be highly susceptible to $\mathrm{vB} \_$PmiS-TH at multiplicities of infection (MOIs) of 1 and 0.001 within $24 \mathrm{~h}$. The planktonic cell count of $P$. mirabilis $(\mathrm{TH})$ was reduced by the phage from $10^{8}$ to $\sim 10^{3} \mathrm{CFU} / \mathrm{mL}$ ( $~ 5 \log$ reduction) within $3 \mathrm{~h}$ at MOIs of 1 and 0.001 (Fig. 5a). However, the higher MOI of the phage (MOI $=1$ ) had a more disruptive effect on the titer of the bacterium than the lower $(\mathrm{MOI}=0.001)$ within the first $3 \mathrm{~h}$. The lytic activity at an MOI of 1 was the same as at an MOI of 0.001 from 3 to $6 \mathrm{~h}$. A moderate increase was observed in the titer of the bacterium after $6 \mathrm{~h}$, but the value stayed significantly lower than that of the control (without phage). Applying the phage (at MOIs of 1 and 0.001 ) with a subminimum inhibitory concentration (MIC) of ampicillin $(8 \mu \mathrm{g} / \mathrm{mL})$ accelerated bacterial growth inhibition compared to applying the phage or the antibiotic alone. During the first hour, an MOI of 1 or 0.001 combined with ampicillin decreased the CFU from $10^{8}$ to $\sim 10^{3} \mathrm{CFU} / \mathrm{mL}$ ( $\sim 5 \log$ reduction) and $\sim 10^{5} \mathrm{CFU} / \mathrm{mL}(\sim 3 \log$ reduction), respectively. The results revealed that simultaneous use of phage and antibiotic produced a synergetic effect on planktonic cultures of $P$. mirabilis $(\mathrm{TH})$. The results of the OD reading with an ELISA plate reader and the bacterial counts were consistent when treated with the phage, the antibiotic, and their combination (Fig. 5b).

Preventive Effect of Bacteriophage $v B \_P m i S-T H$ with or without Ampicillin on Biofilm Formation

The lytic activity of phage vB_PmiS-TH, the antibiotic, and their combination in the prevention of biofilm formation is illustrated in Figure 6a. The results revealed that at both MOIs ( 1 and 0.001 ) the phage caused an $\sim 80 \%$ reduction in biofilm formation by $P$. mirabilis $(\mathrm{TH})$ within $24 \mathrm{~h}$ when compared to the control (without phage) $(p<0.0001)$. Furthermore, the effect of the phage-ampicillin combination at a sub-MIC was higher ( $\sim 85 \%$ reduction in P. mirabilis biofilm formation) than that of the phage alone ( $p<$ $0.0001)$. However, this difference was not significant. 


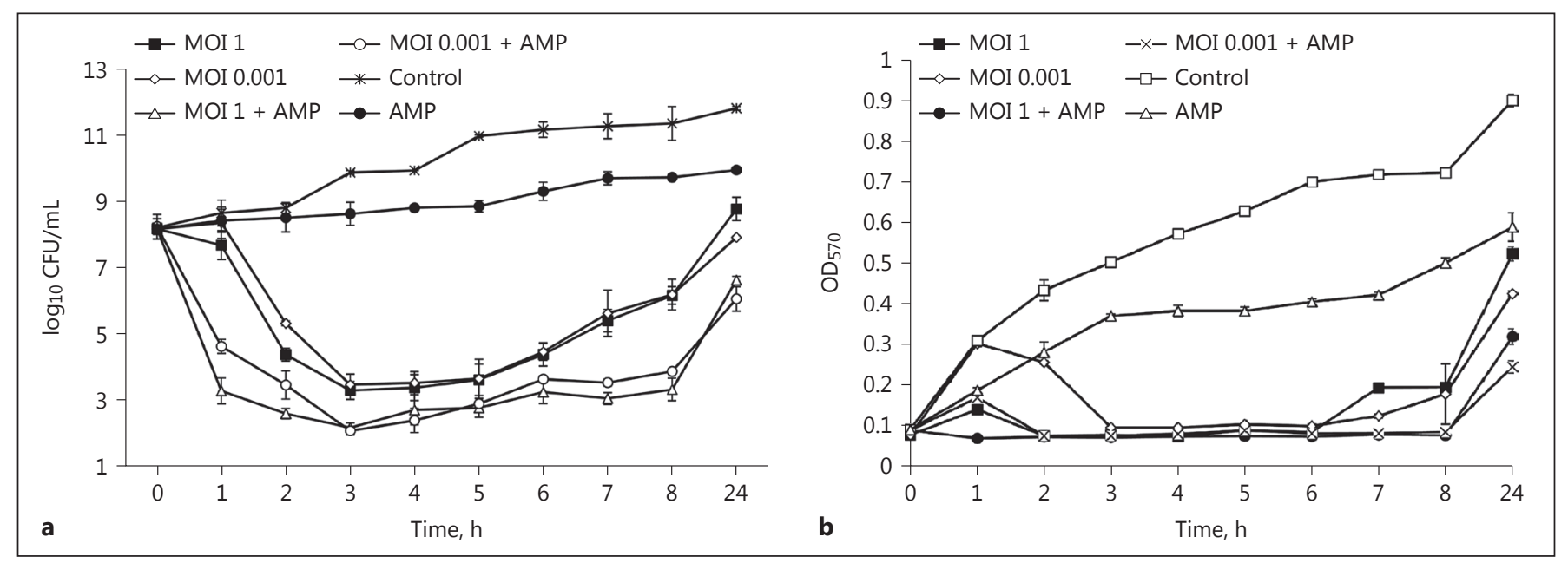

Fig. 5. Effects of treatment with the phage, the antibiotic (AMP), and their combination on the planktonic cell count (a) and OD (b) of $P$. mirabilis. All values are the means of 3 determinations \pm SD. AMP, ampicillin; MOI, multiplicity of infection.

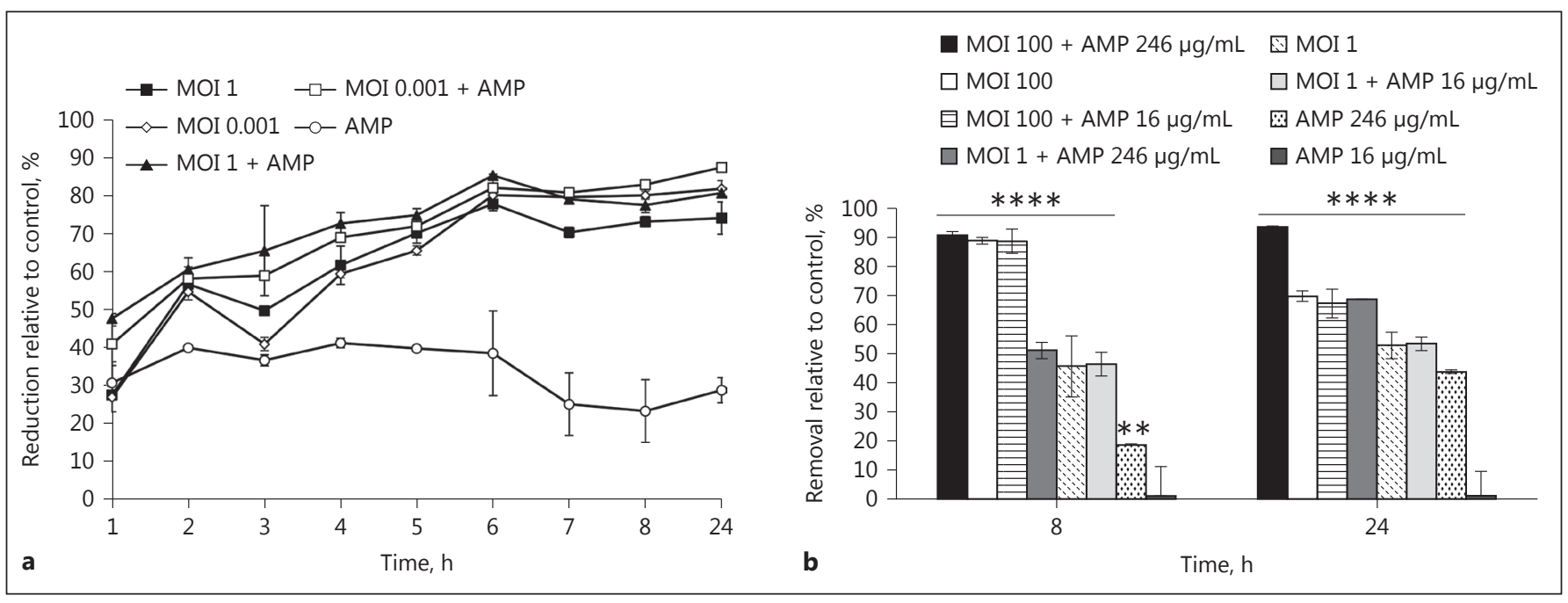

Fig. 6. a Percent reduction of biofilm formation after treatment with phage vB_PmiS-TH, the antibiotic, or their combination compared to untreated controls within $24 \mathrm{~h}$. As analyzed by twoway ANOVA, there was a significant difference between biofilms treated with the phage at an MOI of 1 and those treated with the phage at an MOI of 0.01 in comparison with untreated controls $(p<0.0001)$. The same results were also obtained in comparison

\section{Biofilm Removal Activity of the Phage vB_PmiS-TH} with or without Ampicillin

At MOIs of 100 and 1, the phage vB_PmiS-TH removed $89 \%(p<0.0001)$ and $46 \%(p<0.0001)$ of the biofilm's biomass after $8 \mathrm{~h}$, respectively, when compared to the control (without phage and antibiotic). However, the with the phage-antibiotic treatment $(p<0.0001)$. b Percentage of biofilm removal with the phage, the antibiotic, or their combination compared to untreated controls at 8 and $24 \mathrm{~h}$. Asterisks indicate significant differences in biomass compared with controls as measured by two-way ANOVA (** $\left.p \leq 0.01,{ }^{* * * *} p \leq 0.0001\right)$. All values represent means of 3 determinations \pm SD. AMP, ampicillin; MOI, multiplicity of infection. mentioned values changed to $70 \%(p<0.0001)$ and $53 \%$ $(p<0.0001)$ after $24 \mathrm{~h}$. Ampicillin at a concentration of $246 \mu \mathrm{g} / \mathrm{mL}$ reduced the biofilm's biomass by $19 \%(p<$ $0.01)$ and $44 \%(p<0.0001)$ after 8 and 24 h, respectively. However, the MIC $(16 \mu \mathrm{g} / \mathrm{mL})$ did not decrease the biofilm's biomass, and the result was similar to that of the 

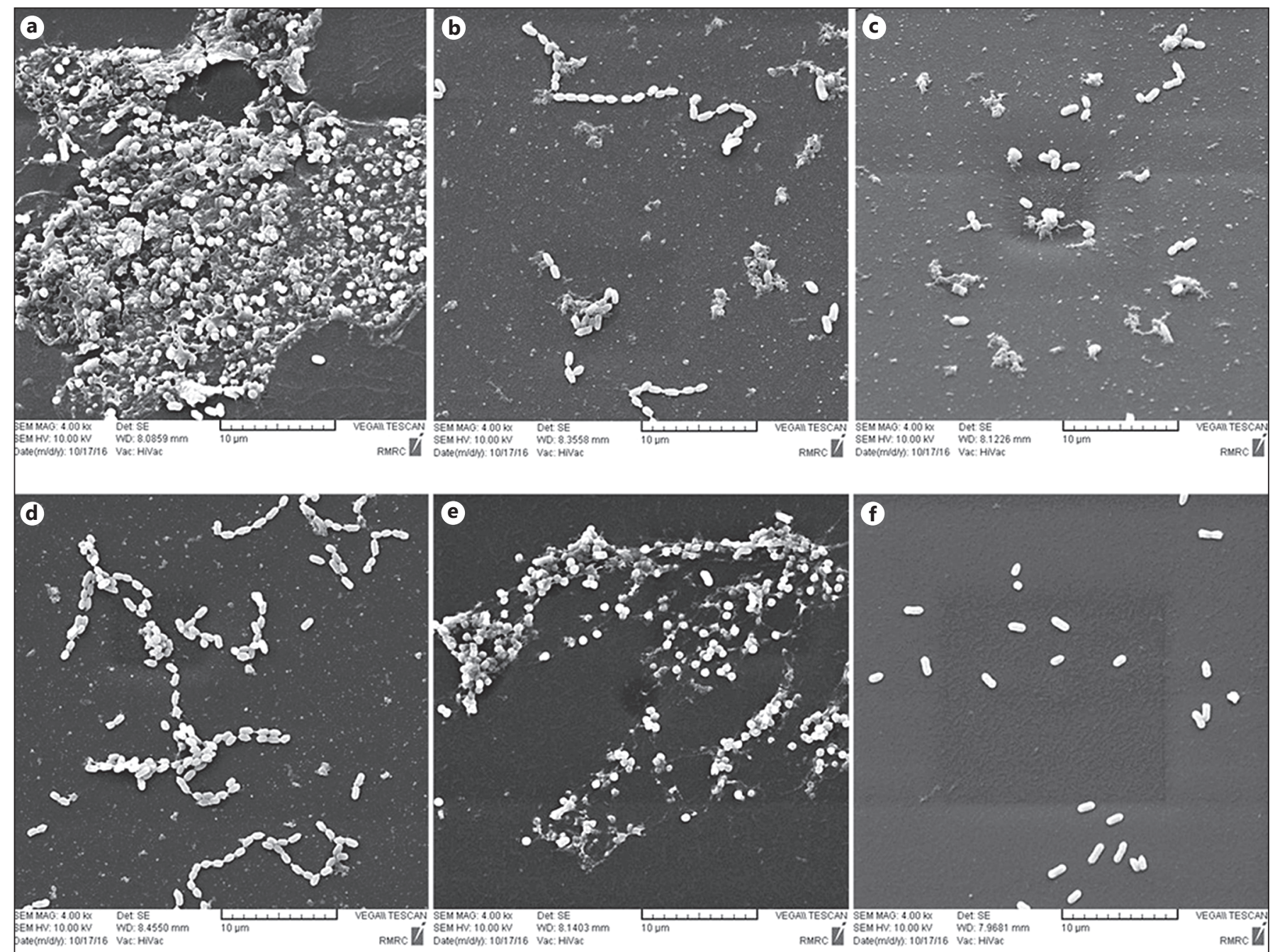

Fig. 7. Scanning electron micrographs. a Micrograph of an untreated urinary catheter surface after biofilm formation by $P$. mirabilis $(\mathrm{TH})$ for $24 \mathrm{~h}$. b, c The catheter's surface pretreated with phage vB_PmiS-TH $($ MOI $=0.001)(\mathbf{b})$ and with phage-ampicillin (sub-minimum inhibitory concentration) (c) for the prevention of biofilm formation after $24 \mathrm{~h}$. d-f Biofilm treated with phage vB_ PmiS-TH $($ MOI $=100)(\mathbf{d})$, the antibiotic $(246 \mu \mathrm{g} / \mathrm{mL})(\mathbf{e})$, and the phage-antibiotic combination (f) for biofilm removal after $24 \mathrm{~h}$. control. A considerable synergistic effect was observed when $P$. mirabilis $(\mathrm{TH})$ was subjected to the phage $\mathrm{vB}_{-}$ PmiS-TH in combination with ampicillin $(246 \mu \mathrm{g} / \mathrm{mL})$ after $24 \mathrm{~h}$. The phage at an MOI of 100 along with the antibiotic $(246 \mu \mathrm{g} / \mathrm{mL})$ removed $91 \%(p<0.0001)$ and $93 \%$ $(p<0.0001)$ of the biofilm after 8 and $24 \mathrm{~h}$, respectively. Meanwhile, at an MOI of 1 the combination with the antibiotic $(246 \mu \mathrm{g} / \mathrm{mL})$ only removed $51 \%(p<0.0001)$ and $68 \%(p<0.0001)$ of the biofilm after 8 and $24 \mathrm{~h}$, respectively (Fig. 6b). At an MOI of 100, the phage alone had a better lytic effect on the removal of 1-day-old $P$. mirabilis (TH) biofilms compared to its usage at an MOI of 1 after 8 and $24 \mathrm{~h}$. Moreover, co-treatment with the phage $\mathrm{vB}_{-}$
PmiS-TH $(\mathrm{MOI}=100)$ and a high dose of ampicillin $(246$ $\mu \mathrm{g} / \mathrm{mL}$ ) had the highest biofilm removal effect after $24 \mathrm{~h}$.

\section{Scanning Electron Microscopy}

The P. mirabilis (TH) biofilms treated with the phage or the phage-antibiotic combination were observed by scanning electron microscopy (SEM) (Fig. 7). Biofilm formation was significantly suppressed in both the phagetreated and the phage-antibiotic-treated catheters (Fig. 7b, c). As shown in Figure 7f, biofilm removal under exposure to the phage-antibiotic combination was more thorough than that with the phage or the antibiotic alone (Fig. 7d, e). 


\section{Discussion}

In recent years, with the spread of antibiotic-resistant pathogenic bacteria, many researchers have reported the successful treatment of human and animal infections with bacteriophage therapy [Harper et al., 2014; Sulakvelidze et al., 2001]. In the present study, the phage vB_PmiS-TH showed a narrow host range with lytic effects only against $P$. mirabilis $(\mathrm{TH})$ and $P$. mirabilis ATCC 43071. Many phages have been described that are highly specific for host cell surface receptors [Jamal et al., 2015b; Piracha et al., 2014]. This host specificity of phages is described by Shen et al. [2012] as a major limitation to therapy. Therefore, a phage cocktail could be suggested for the therapy of bacterial infection in an emergency [Shen et al., 2012].

According to our results, the phage vB_PmiS-TH was resistant to high temperatures and remained stable up to $75^{\circ} \mathrm{C}$ for $1 \mathrm{~h}$, but lost its lytic activity against the host at $80^{\circ} \mathrm{C}$. On the other hand, the phage showed good stability in acidic and alkaline conditions over a wide $\mathrm{pH}$ range (3-11). Urease production in P. mirabilis plays an important role in the formation of a crystalline biofilm in UTIs. The urine's $\mathrm{pH}$ increases to $8-9$ as a result of bacterial urease action. However, accumulation of acidic substances may sometimes reduce the $\mathrm{pH}$ in the matrix of the biofilm [Carson et al., 2010]. These fluctuations in $\mathrm{pH}$ may lead to the destruction of antibiotics in such infections. Thus, this feature of the phage could be an advantage over antibiotics in the treatment of UTIs caused by P. mirabilis and its biofilm.

A number of divalent cofactor cations can influence phage adsorption and infection rates [Watanabe and Takesue, 1972]. They may also increase the virion concentration on the surface of the host and change the structure of receptors. Therefore, access to receptors or phage nucleic acid translocation would be accelerated [Jamal et al., 2015b]. In our study, the phage vB_PmiS-TH showed considerable infectivity with $10 \mathrm{mM} \mathrm{CaCl} 2$ or $\mathrm{MgCl}_{2}$ compared to the phage without cations. The results are in agreement with previous observations emphasizing that $\mathrm{Ca}^{2+}$ and $\mathrm{Mg}^{2+}$ stabilize the interaction of virions with binding sites during adsorption [Jamal et al., 2015b; Li and Zhang, 2014].

The phage vB_PmiS-TH at two MOIs of 1 and 0.001 reduced the titer of planktonic $P$. mirabilis from $10^{8}$ to $\sim 10^{3} \mathrm{CFU} / \mathrm{mL}$ within $3 \mathrm{~h}$ and remained constant for about $6 \mathrm{~h}$. The effect of the higher MOI was slightly greater, but not significantly so. Then, the titer of the bacterium was increased over time up to $24 \mathrm{~h}$ (Fig. 5a). This could be attributed to the emergence of phage-resistant mutant strains [Shen et al., 2012].

Phage vB_PmiS-TH combined with a sub-MIC of ampicillin had a synergetic effect on planktonic $P$. mirabilis (TH) cells. This could be correlated to the filamentation of bacterial cells in the presence of sub-MICs of $\beta$-lactam antibiotics, which allows faster assembly of the phage. This may have resulted from larger and altered pools of precursors obtainable in phage assembly, accelerating cell lysis [Comeau et al., 2007]. Thus, the use of a phage-antibiotic combination could be an advantage over using a phage alone to prevent the emergence of phage-resistant phenotypes, resulting in faster elimination of bacteria than with the phage alone [Chibeu et al., 2012; Shen et al., 2012].

The phage vB_PmiS-TH alone showed great potential in the prevention of biofilm formation ( $\sim 80 \%$ reduction) by $P$. mirabilis (TH) after $24 \mathrm{~h}$. The preventive activity of the phage-antibiotic combination $(\sim 85 \%)$ was higher than that of the phage alone. Carson et al. [2010] studied the impact of phages on the prevention of biofilm formation on Foley catheters and reported a $90 \%$ reduction in P. mirabilis biofilm formation on bacteriophage-treated catheters compared to controls. This is consistent with the results obtained in the present study, which suggests that pretreatment of catheters with bacteriophages alone or combined with antibiotics could be more effective in the prevention of biofilm formation by $P$. mirabilis than pretreatment with antibiotics alone.

In the present study, the phage vB_PmiS-TH at an MOI of 100 combined with ampicillin at $246 \mu \mathrm{g} / \mathrm{mL}$ demonstrated the greatest biofilm removal activity compared to the phage or the antibiotic alone. Several studies have investigated the effects of phages alone or combined with antibiotics on the removal of bacterial biofilms [Bedi et al., 2009; Rahman et al., 2011; Ryan et al., 2012]. Bedi et al. [2009] reported that a high concentration of an antibiotic with a phage significantly reduces the bacterial load of biofilm when compared to a phage or an antibiotic alone. The higher resistance of biofilm to ampicillin compared to the planktonic state of $P$. mirabilis could be attributed to decreased antibiotic diffusion through the extensive biofilm matrix, where there is an increase in alginate synthesis [Nouraldin et al., 2016]. Nevertheless, phages can attach to specific receptors, penetrate, and cause biofilm disruption and cell lysis. This may be due to the phage-encoded enzyme depolymerase, which degrades the capsular polysaccharide of the biofilm and facilitates the fine spread of the phage. The path that is made by the phage while passing through the biofilm fa- 
cilitates diffusion of the antibiotic inside the biofilm at higher concentrations than those achieved when the various barriers of intact biofilm are still present [Bedi et al., 2009; Donlan, 2009; Harper et al., 2014].

\section{Conclusions}

The phage vB_PmiS-TH demonstrates a high lytic activity against $P$. mirabilis (TH) isolated from UTIs in both planktonic and biofilm forms. This activity decreases over time, especially in removing older biofilms. The results suggest that the combination therapy is more effective in biofilm removal than either of the therapies alone. Moreover, it can prevent the development of resistant mutants, which would otherwise develop rapidly in the case of exposure to antibiotics or phages. However, further study of the antibacterial activity of this phage in live host cells will be necessary to develop the phage's applicability.

\section{Experimental Procedures}

\section{Bacterial Identification}

A clinical $P$. mirabilis strain (TH) isolated from UTI was obtained from Mousavi Hospital in Gorgan, Iran. Biochemical tests were used to characterize the P. mirabilis strain [Al-Jumaily and Zgaer, 2016]. The strain then was confirmed by $16 \mathrm{~S}$ rRNA gene sequencing and later amplified by PCR using universal 16S rRNA primers: 16S-R ( $5^{\prime}$ TTC TTT TGC AAC CCA CTC CCA $\left.3^{\prime}\right)$, and 16S-F (5' CGT GCT ACA ATG GCG CAT AC 3') (metabion International AG, Planegg, Germany). The amplification conditions were set as follows: initial denaturation at $95^{\circ} \mathrm{C}$ for $5 \mathrm{~min}$ ( 1 cycle), denaturation at $94^{\circ} \mathrm{C}$ for $1 \mathrm{~min}$, annealing at $60^{\circ} \mathrm{C}$ for $1 \mathrm{~min}$, extension at $72^{\circ} \mathrm{C}$ for $1 \mathrm{~min}$ ( 35 cycles), and 1 final elongation step at $72^{\circ} \mathrm{C}$ for $7 \mathrm{~min}$. The purified PCR product was sequenced (Macrogen, $\mathrm{SK}$ ) and identified by alignment using BLAST (National Center for Biotechnology Information, USA).

\section{Bacteriophage Isolation and Purification}

Sewage samples were collected from various aquatic ecosystems in the north of Iran for phage isolation. The samples were centrifuged at 8,800 $\mathrm{g}$ for $10 \mathrm{~min}$ (Eppendorf $5810 \mathrm{R}$; Eppendorf AG, Hamburg, Germany). Then, $20 \mathrm{~mL}$ of the supernatant was mixed with $20 \mathrm{~mL}$ of $2 \times$ brain heart infusion (BHI) broth containing the $P$. mirabilis (TH) strain in the exponential phase. The bacterial cells were centrifuged after $24 \mathrm{~h}$ of incubation at $37^{\circ} \mathrm{C}$, and the supernatant was filtered through a $0.22-\mu \mathrm{m}$ membrane filter (Gilson, Dunstable, UK). The presence of bacteriophage infecting P. mirabilis was confirmed by adding $100 \mu \mathrm{L}$ of an overnight culture $\left(10^{8} \mathrm{CFU} / \mathrm{mL}\right)$ to $5 \mathrm{~mL}$ molten $0.7 \%$ soft $\mathrm{BHI}$ agar at $45^{\circ} \mathrm{C}$ and then pouring on the surface of the solid agar (BHI with $1.5 \%$ agar). After the top agar layer had solidified, $20 \mu \mathrm{L}$ of phage filtrate was spotted onto the top agar layer of the bacterial lawn. To purify the isolated phage, an aliquot $(100 \mu \mathrm{L})$ of the filtrate was gently mixed with $100 \mu \mathrm{L}$ of an overnight bacterial culture and $5 \mathrm{~mL}$ of molten soft agar (BHI with $0.7 \%$ agar) at $45^{\circ} \mathrm{C}$, and this mixture was overlaid onto $1.5 \% \mathrm{BHI}$ agar to make a double-layered agar plate. A single plaque visible after overnight incubation at $37^{\circ} \mathrm{C}$ was picked and suspended in $1 \mathrm{~mL} \mathrm{SM}$ buffer $\left(\mathrm{NaCl}, 5.8 \mathrm{~g} ; \mathrm{MgSO}_{4} \cdot 7 \mathrm{H}_{2} \mathrm{O}\right.$, 2 g; $1 \mathrm{M}$ Tris-Cl, pH 7.5, $50 \mathrm{~mL}$; $\%$ gelatin, $5 \mathrm{~mL}$; added $\mathrm{ddH}_{2} \mathrm{O}$ to $1,000 \mathrm{~mL}$ ). This procedure was repeated 3 times to ensure the purity of the isolated phage. The phage titer was also determined with the double-layered agar plate technique, as described above [Ghasemi et al., 2014a; Komijani et al., 2016].

\section{Host Range Determination}

The host range of the isolated phage vB_PmiS-TH was assessed by the spot test method as described previously [Duraisamy et al., 2015; Zimmer et al., 2002]. The assays were performed on a range of gram-positive and gram-negative, clinically isolated pathogenic bacteria that were obtained from the Department of Microbiology, Golestan University of Medical Sciences, Iran (Table 1).

\section{Thermal and $p H$ Stability}

The stability of the phage $\left(1.3 \times 10^{11} \mathrm{PFU} / \mathrm{mL}\right)$ in different thermal conditions $\left(37-80^{\circ} \mathrm{C}\right.$ ) and $\mathrm{pH}$ values $(2-12)$ (for 1 and $24 \mathrm{~h}$ at $37^{\circ} \mathrm{C}$ ) was assessed using a previously described method [Jamal et al., 2015a].

Adsorption Rate, Latent Period, and Phage Burst Size

As described previously [Jamal et al., 2015b], $25 \mathrm{~mL}$ of BHI broth containing $P$. mirabilis $(\mathrm{TH})$ in the exponential phase were mixed with $100 \mu \mathrm{L}$ of the phage with and without the addition of $\mathrm{MgCl}_{2}$ or $\mathrm{CaCl}_{2}$ at a final concentration of $10 \mathrm{mM}$. Samples were taken at different time intervals $(0,5,10,15$, and $20 \mathrm{~min})$ to investigate the free phage particles in the test and control (without divalent ions) samples. The phage titers were estimated by the soft agar overlay method.

In order to determine the latent time and burst size of the phage, the one-step growth assay was performed using a standardized method with some modifications [Yang et al., 2010]. First, 5 $\mathrm{mL}$ of $P$. mirabilis $(\mathrm{TH})$ cells were incubated to the mid-exponential phase $\left(\mathrm{OD}_{600}=0.5\right)$. The bacterial cells were obtained by centrifugation at 7,000 $\mathrm{g}$ for $10 \mathrm{~min}$. The pellet was resuspended in 2 $\mathrm{mL}$ of BHI broth with a concentration of $10^{9} \mathrm{CFU} / \mathrm{mL}$ and then mixed with $100 \mu \mathrm{L}$ of the phage $\left(10^{8} \mathrm{PFU} / \mathrm{mL}\right)$. Following $10 \mathrm{~min}$ of incubation for attachment of the phage to bacterial cells, the mixture was centrifuged at $13,000 \mathrm{~g}$ for $1 \mathrm{~min}$ to eliminate unabsorbed free phages. The resulting pellet was resuspended in $20 \mathrm{~mL}$ of fresh BHI broth and incubated at $37^{\circ} \mathrm{C}$. Then, $100 \mu \mathrm{L}$ of the samples were taken at 10 -min intervals up to $120 \mathrm{~min}$, immediately diluted, and titrated by phage plaque counting using the soft agar overlay method [Li and Zhang, 2014; Yang et al., 2010].

\section{Phage Morphology by Transmission Electron Microscopy}

The sample for electron microscopic examination was prepared as follows: $10 \mu \mathrm{L}$ of phage suspension was dropped on the surface of a carbon-coated copper grid. The grid was then negatively stained with $2 \%$ uranyl acetate for $30 \mathrm{~s}$, excess stain was removed, and the copper grid was air-dried. Finally, the grid was examined under a Fei Philips EM 208S electron microscope (Japan) at an operating voltage of $100 \mathrm{kV}$ [Ghasemi et al., 2014b]. 
Extraction of Phage DNA and Restriction Analyses

Bacteriophagic genomic DNA was isolated by a method described previously [Sambrook et al., 1989; Zamani et al., 2014]. The extracted DNA was subjected to the restriction enzymes EcoRI, HindIII, NdeI, EcoRV, PstI, and BamHI, according to the manufacturer's instructions (Thermo Fisher Scientific, Germany). Finally, the size of the genome was approximately determined with SequentiX GelAnalyzer software [Ghasemi et al., 2014c].

\section{Minimum Inhibitory Concentration}

The MIC of ampicillin (AppliChem GmbH, Darmstadt, Germany) for P. mirabilis (TH) was determined using the CLSI broth microdilution protocol [Patel et al., 2014].

\section{Susceptibility of Planktonic Cells}

The culture of $P$. mirabilis (TH) clinical isolates grown in medium (BHI broth supplemented with $1 \%$ saccharose) (OD $=0.1$ at $600 \mathrm{~nm} ; 1.5 \times 10^{8} \mathrm{CFU} / \mathrm{mL}$ ) was distributed in a 96-well sterile polystyrene microtiter plate $(190 \mu \mathrm{L}$ in each well). Next, $10 \mu \mathrm{L}$ of the phage at MOIs of 1 and 0.001 was added, and was incubated at $37^{\circ} \mathrm{C}$ for various time intervals (1-24 h) [Sagar et al., 2015]. Samples were collected at the appropriate time points and $\mathrm{OD}_{570}$ was measured. An aliquot from each well was removed, diluted 100fold, and plated in triplicate on BHI agar (3.7\% agar) to determine viable counts [Jamal et al., 2015b]. In order to determine the effect of the phage and the antibiotic against planktonic culture, simultaneously, $190 \mu \mathrm{L}$ of bacterial culture $\left(1.5 \times 10^{8} \mathrm{CFU} / \mathrm{mL}\right)$ was mixed with $10 \mu \mathrm{L}$ of the phage at different titers (MOIs of 1 and 0.001 ). Then, $100 \mu \mathrm{L}$ of the mixtures was added to a $96-$ well microtiter plate. Finally, $100 \mu \mathrm{L}$ of ampicillin at a sub-MIC $(8 \mu \mathrm{g} / \mathrm{mL})$ was added to the wells. The plates were incubated at $37^{\circ} \mathrm{C}$ for 1,2 , $3,4,5,6,7,8$, and $24 \mathrm{~h}$, and measured as described above. Wells containing culture with/without the antibiotic (no phage) were used as controls. This experiment was repeated 3 times [Bedi et al., 2009; Nouraldin et al., 2016].

\section{Prevention of Biofilm Formation}

To prevent biofilm formation, P. mirabilis (TH) culture $\left(\mathrm{OD}_{600}=0.1\right)$ was treated with the phage alone and the phageantibiotic combination in 96 -well sterile polystyrene microtiter plates. After incubation at $37^{\circ} \mathrm{C}$ for $24 \mathrm{~h}(1-24 \mathrm{~h})$, the content of the wells was discarded and the wells were thoroughly washed 3 times with sterile PBS. The total biomass of the biofilm was determined by crystal violet staining according to the method described previously [Carson et al., 2010]. P. mirabilis (TH) suspension without both phage and antibiotic was used as a control.

\section{Biofilm Removal}

The isolated phage's ability to remove $P$. mirabilis biofilm was assessed alone or combined with the antibiotic according to Chhibber et al. [2013], with some modifications in microtiter plates. A bacterial suspension $\left(1.5 \times 10^{8} \mathrm{CFU} / \mathrm{mL}\right)$ was prepared in the medium (BHI broth supplemented with $1 \%$ saccharose). Then, 200 $\mu \mathrm{L}$ of the suspension was added to microtiter plate wells. After incubation at $37^{\circ} \mathrm{C}$ for $24 \mathrm{~h}$, planktonic cells were removed and the biofilms were treated with phage, antibiotic, and their combination [Chhibber et al., 2013]. The phage and ampicillin were used at different MOIs (1 and 100) and concentrations (including an MIC of $16 \mu \mathrm{g} / \mathrm{mL}$ and about 15-fold higher than the MIC value), respectively [Rahman et al., 2011]. After treatment with the phage and/or ampicillin, the plates were incubated at $37^{\circ} \mathrm{C}$ for 8 and 24 $\mathrm{h}$. The phage and antibiotic were removed and the wells were rinsed 3 times with PBS. The total biomass of the biofilm was measured by crystal violet staining with the assay described previously [Carson et al., 2010]. Each experiment was performed 3 times.

\section{Examination of Biofilms with SEM}

Effects of the phage, ampicillin, and their combination in preventing or removing biofilm on the catheter surfaces were visualized by SEM (HiVac, VEGAIITESCAN SEM; TESCAN, Brno, Czech Republic) according to the method previously described [Curtin and Donlan, 2006; Rahman et al., 2011].

\section{Statistical Analyses}

Statistical analysis of the data was performed by $t$ test, one-way repeated-measures ANOVA, and two-way ANOVA with GraphPad Prism 6.05.

\section{Acknowledgements}

This study was financially supported by a joint grant from the University of Isfahan and Golestan University of Medical Sciences, Iran (35/219525).

\section{References}

Al-Jumaily E, Hussein Zgaer S: Multidrug resistant Proteus mirabilis isolated from urinary tract infection from different hospitals in Baghdad City. Int J Curr Microbiol Appl Sci 2016;5:390-399.

Bedi MS, Verma V, Chhibber S: Amoxicillin and specific bacteriophage can be used together for eradication of biofilm of Klebsiella pneumoniae B5055. World J Microbiol Biotechnol 2009;25:1145-1151.
Burall LS, Harro JM, Li X, Lockatell CV, Himpsl SD, Hebel JR, Johnson DE, Mobley HL: Proteus mirabilis genes that contribute to pathogenesis of urinary tract infection: identification of 25 signature-tagged mutants attenuated at least 100-fold. Infect Immun 2004;72: 2922-2938.

-Carson L, Gorman SP, Gilmore BF: The use of lytic bacteriophages in the prevention and eradication of biofilms of Proteus mirabilis and Escherichia coli. FEMS Immunol Med Microbiol 2010;59:447-455.
Cerca N, Oliveira R, Azeredo J: Susceptibility of Staphylococcus epidermidis planktonic cells and biofilms to the lytic action of staphylococcus bacteriophage K. Lett Appl Microbiol 2007;45:313-317.

-Chhibber S, Nag D, Bansal S: Inhibiting biofilm formation by Klebsiella pneumoniae B5055 using an iron antagonizing molecule and a bacteriophage. BMC Microbiol 2013;13:174.
Phage and Ampicillin Application against Forms of Proteus mirabilis
J Mol Microbiol Biotechnol 2018;28:37-46 DOI: $10.1159 / 000487137$ 
Chibeu A, Lingohr EJ, Masson L, Manges A, Harel J, Ackermann HW, Kropinski AM, Boerlin P: Bacteriophages with the ability to degrade uropathogenic Escherichia coli biofilms. Viruses 2012;4:471-487.

- Comeau AM, Tétart F, Trojet SN, Prère MF, Krisch H: Phage-antibiotic synergy (PAS): $\beta$-lactam and quinolone antibiotics stimulate virulent phage growth. PLoS One 2007;2: e799.

Curtin JJ, Donlan RM: Using bacteriophages to reduce formation of catheter-associated biofilms by Staphylococcus epidermidis. Antimicrob Agents Chemother 2006;50:1268-1275.

Donlan RM: Preventing biofilms of clinically relevant organisms using bacteriophage. Trends Microbiol 2009;17:66-72.

Duraisamy N, Nachimuthu R, Vaithilingam K, Pandiyan R, Ebenezer KS, Velu RK: Distribution, isolation and characterization of lytic bacteriophages against multi-drug resistant and extended-spectrum of $\beta$-lactamase producing pathogens from hospital effluents. Asian J Pharm Clin Res 2015;8:384-389.

Ghasemi SM, Bouzari M, Emtiazi G: Preliminary characterization of Lactococcus garvieae bacteriophage isolated from wastewater as a potential agent for biological control of lactococcosis in aquaculture. Aquac Int 2014a;22: 1469-1480.

-Ghasemi SM, Bouzari M, Baygloo NS, Chang HI: Insights into new bacteriophages of Lactococcus garvieae belonging to the family Podoviridae. Arch Virol 2014b;159:2909-2915.

-Ghasemi SM, Bouzari M, Yoon BH, Chang HI: Comparative genomic analysis of Lactococcus garvieae phage WP-2, a new member of Picovirinae subfamily of Podoviridae. Gene 2014c; 551:222-229.

- Harper DR, Parracho HM, Walker J, Sharp R, Hughes G, Werthén M, Lehman S, Morales S: Bacteriophages and biofilms. Antibiotics 2014;3:270-284.

-Jacobsen SM, Shirtliff ME: Proteus mirabilis biofilms and catheter-associated urinary tract infections. Virulence 2011;2:460-465.

- Jamal M, Hussain T, Das CR, Andleeb S: Isolation and characterization of a Myoviridae MJ1 bacteriophage against multi-drug resistant Escherichia coli 3. Jundishapur J Microbiol 2015a;8:e25917.
Jamal M, Hussain T, Das CR, Andleeb S: Characterization of Siphoviridae phage $\mathrm{Z}$ and studying its efficacy against multidrug-resistant Klebsiella pneumoniae planktonic cells and biofilm. J Med Microbiol 2015b;64(pt 4):454462.

Kirby AE: Synergistic action of gentamicin and bacteriophage in a continuous culture population of Staphylococcus aureus. PLoS One 2012;7:e51017.

Komijani M, Bouzari M, Rahimi F: Detection and characterization of a novel lytic bacteriophage (vB-KpneM-Isf48) against Klebsiella pneumoniae isolates from infected wounds carrying antibiotic-resistance genes (TEM, SHV, and $C T X-M$ ). Iran Red Crescent Med J 2016; 19:e34475.

Kropinski AM, Prangishvili D, Lavigne R: Position paper: the creation of a rational scheme for the nomenclature of viruses of Bacteria and Archaea. Environ Microbiol 2009;11: 2775-2777.

Li L, Zhang Z: Isolation and characterization of a virulent bacteriophage SPW specific for Staphylococcus aureus isolated from bovine mastitis of lactating dairy cattle. Mol Biol Rep 2014;41:5829-5838.

Maszewska A, Wójcik E, Ciurzyńska A, Wojtasik A, Piątkowska I, Dastych J, Różalski A: Differentiation of polyvalent bacteriophages specific to uropathogenic Proteus mirabilis strains based on the host range pattern and RFLP. Acta Biochim Pol 2016;63:303-310.

-Nouraldin AAM, Baddour MM, Harfoush RAH, Essa SAM: Bacteriophage-antibiotic synergism to control planktonic and biofilm producing clinical isolates of Pseudomonas aeruginosa. Alexandria J Med 2016;52:99-105.

-Nzakizwanayo J, Hanin A, Alves DR, McCutcheon B, Dedi C, Salvage J, Knox K, Stewart B, Metcalfe A, Clark J, et al: Bacteriophage can prevent encrustation and blockage of urinary catheters by Proteus mirabilis. Antimicrob Agents Chemother 2015;60:1530-1536.

Patel J, Cockerill F, Alder J, Bradford P, Eliopoulos G, Hardy D: Performance Standards for Antimicrobial Susceptibility Testing; Twenty-Fourth Informational Supplement. Wayne, CLSI, 2014, vol 34.
Piracha ZZ, Saeed U, Khurshid A, Chaudhary $\mathrm{WN}$ : Isolation and partial characterization of virulent phage specific against Pseudomonas aeruginosa. Glob J Med Res 2014;14:1-8.

Rahman M, Kim S, Kim SM, Seol SY, Kim J: Characterization of induced Staphylococcus aureus bacteriophage SAP-26 and its anti-biofilm activity with rifampicin. Biofouling 2011;27: 1087-1093.

Ryan EM, Alkawareek MY, Donnelly RF, Gilmore BF: Synergistic phage-antibiotic combinations for the control of Escherichia coli biofilms in vitro. FEMS Immunol Med Microbiol 2012;65:395-398.

Sagar SS, Kumar R, Kaistha SD: Inhibition of different stages of biofilm of Pseudomonas aeruginosa PA01 by isolated bacteriophage P2. Asian J Pharm Clin Res 2015;8:296-299.

Sambrook J, Fritsch EF, Maniatis T: Molecular Cloning. New York, Cold Spring Harbor Laboratory Press, 1989.

- Shen GH, Wang JL, Wen FS, Chang KM, Kuo CF, Lin $\mathrm{CH}$, Luo $\mathrm{HR}$, Hung $\mathrm{CH}$ : Isolation and characterization of $\varphi \mathrm{km} 18 \mathrm{p}$, a novel lytic phage with therapeutic potential against extensively drug resistant Acinetobacter baumannii. PLoS One 2012;7:e46537.

- Sillankorva S, Oliveira R, Vieira MJ, Sutherland I, Azeredo J: Bacteriophage $\Phi$ S1 infection of Pseudomonas fluorescens planktonic cells versus biofilms. Biofouling 2004;20:133-138.

-Sulakvelidze A, Alavidze Z, Morris JG Jr: Bacteriophage therapy. Antimicrob Agents Chemother 2001;45:649-659.

Watanabe K, Takesue S: The requirement for calcium in infection with Lactobacillus phage. J Gen Virol 1972;17:19-30.

- Yang H, Liang L, Lin S, Jia S: Isolation and characterization of a virulent bacteriophage $\mathrm{AB} 1$ of Acinetobacter baumannii. BMC Microbiol 2010;10:131.

Zamani I, Bouzari M, Emtiazi G, Ghasemi SM, Chang HI: Complete genome sequence of a novel phage, vB_MoxS-ISF9, infecting methylotrophic Microbacterium: first report of a virulent Microbacterium phage. Arch Virol 2014; 159:2537-2540.

Zimmer M, Scherer S, Loessner MJ: Genomic analysis of Clostridium perfringens bacteriophage $\varphi 3626$, which integrates into guaA and possibly affects sporulation. J Bacteriol 2002; 184:4359-4368. 